\section{Os incentivos fiscais aos agrotóxicos como política contrária à saúde e ao meio ambiente}

\author{
Fiscal incentives for pesticides as an anti-health \\ and anti-environmental policy
}

Los incentivos fiscales a los pesticidas como política contraria a la salud y al medioambiente
Lucas Neves da Cunha 1

Wagner Lopes Soares 2

\section{Resumo}

Os agrotóxicos são produtos perigosos e os incentivos fiscais associados a eles impactam direta e indiretamente os recursos públicos empregados na saúde do Brasil, pois estimulam o seu uso. Desse modo, este artigo teve como objetivo estimar a desoneração fiscal sobre os agrotóxicos no país em 2017. A metodologia incluiu a pesquisa bibliográfica das legislações tributárias de referência, seguida das estimativas calculadas com base nas despesas com agrotóxicos reveladas no último Censo Agropecuário e nos dados de comércio exterior. $O$ montante calculado e consolidado no Brasil é da ordem de BRL 9,8 bilhões, sendo que BRL 6,2 bilhões correspondem à desoneração de ICMS (Imposto sobre Circulação de Mercadorias e Serviços), BRL 1,7 bilhão do IPI (Imposto sobre Produtos Industrializados), BRL 1,5 bilhão de contribuições sociais e BRL 472 milhões de Imposto de Importação. Os resultados encontrados demonstram que a eficiência do uso de agroquímicos está artificialmente superestimada devido à desoneração fiscal. Dessa forma, a tributação apresenta-se como meio potencial de reduzir a demanda por agrotóxicos, mitigando as externalidades negativas e fortalecendo práticas agrícolas alternativas e ecologicamente equilibradas.

Agrotóxicos; Isenção Fiscal; Indústria Agropecuária

\author{
Correspondência \\ L. N. Cunha \\ Rua Araujo Lima 103, Rio de Janeiro, RJ 20541-050, Brasil. \\ lucas.nevesc@gmail.com \\ 1 Universidade Federal Rural do Rio de Janeiro, Seropédica, \\ Brasil. \\ 2 Instituto Brasileiro de Geografia e Estatística, Rio de Janeiro, \\ Brasil.
}




\section{Introdução}

Este artigo tem como objetivo discutir os efeitos dos incentivos fiscais concedidos aos agrotóxicos e estimar o quantitativo monetário referente a eles que o Poder Público deixou de arrecadar em 2017. Tais incentivos são aplicados a esses insumos agrícolas desde o final da década de 1960 e perduram até os dias de hoje, com benesses não só ao produto final, mas também aos equipamentos de aplicação, como é o caso dos tributos de importação de aviões de uso agrícola 1. No entanto, o Brasil apenas seguiu uma tendência mundial em subsidiar agrotóxicos e fertilizantes, pois os incentivos governamentais faziam parte de uma política mundial de incentivo à revolução verde nos países em desenvolvimento. Um estudo realizado pela Organização das Nações Unidas para a Alimentação e a Agricultura (FAO) em 38 países em desenvolvimento revelou que 26 deles subsidiavam o uso de agroquímicos 2 , servindo o Estado como uma espécie de "adubo" para o crescimento do uso destes produtos.

Os incentivos fiscais são uma espécie de instrumento econômico dos Estados cuja ideia de concedê-los à determinada atividade, produto ou setor econômico consiste em estimular a produção, o que gera, consequentemente, algum retorno para a sociedade, como a geração de empregos, por exemplo. O principal argumento da desoneração dos agrotóxicos está fundado no princípio da seletividade, uma vez que estes são insumos, segundo os que advogam o seu uso, "necessários" para a produção agrícola. Conforme essa corrente, ele confere um ganho de produtividade ao produtor, aumentando a oferta de alimentos e reduzindo seus preços. Dessa forma, desonera-se a cesta básica e promove-se em tese maior acesso aos alimentos.

Contudo, para a concessão de benefícios fiscais espera-se uma avaliação periódica dos possíveis retornos sociais, estabelecendo como critério de eficiência metas de resultados, a fim de legitimar a permanência ou não da política fiscal em questão ${ }^{3}$. Em 2017, um estudo do Tribunal de Contas da União (TCU) concluiu que os incentivos fiscais concedidos no país, em muitos casos, não têm acompanhamento de órgãos fiscalizadores que averiguem essa eficácia e podem invariavelmente extrapolar os prazos razoáveis e inicialmente estipulados de tais medidas 4 . O exemplo dos agrotóxicos, as isenções fiscais concedidas pelo Convênio ICMS no 100/1997 5 do Conselho Nacional de Política Fazendária (CONFAZ), que reduz a base de cálculo do Imposto sobre Circulação de Mercadorias e Serviços (ICMS) em 60\%, ultrapassam mais de 20 anos, sendo o mesmo renovado pelo menos 17 vezes desde o início da sua vigência.

No mesmo estudo, o TCU consolida a renúncia fiscal dos tributos federais concedidos aos agrotóxicos no período de 2010 a 2017 e, conforme o demonstrativo de gastos tributário feito pela Receita Federal, o resultado foi de 8,9 bilhões de reais relativos à alíquota zero das Contribuições Sociais (COFINS - Contribuição para o Financiamento da Seguridade Social) e do PIS/PASEP (Programa de Integração Social e o Programa de Formação do Patrimônio do Servidor Público) 4 .

O Quadro 1 apresenta os tributos que desoneram a utilização de agrotóxicos. São impostos e contribuições sociais, a saber: ICMS, Imposto sobre Produtos Industrializados (IPI) e Imposto de Importação (II); e o COFINS, para o PIS e o PASEP. Desses tributos, a instituição do ICMS é competência dos estados e do Distrito Federal, e dos demais da União 6.

Dos tributos envolvidos na tributação da cadeia produtiva dos agrotóxicos, o incentivo fiscal concedido no âmbito do ICMS, do PIS/PASEP e da COFINS é considerado gasto tributário, pois os respectivos sistemas tributários de referência são excepcionados. Por outro lado, no caso do IPI e II, os benefícios fiscais não são exceção ao funcionamento destes impostos 4,7. Desse modo, os benefícios fiscais no âmbito do ICMS e das contribuições sociais são classificados como renúncia fiscal, mas no caso do IPI e II são desonerações em sentido amplo.

No entanto, mesmo sem excepcionar o sistema tributário de referência, a desoneração em sentido amplo também gera um não recolhimento de receita ao erário e tem implicações na tomada de decisão do agente econômico. Portanto, ambos os valores são estimados neste artigo por influenciarem as relações de mercado no ponto de vista econômico.

É importante salientar que o incentivo estatal pró-agrotóxicos nas políticas públicas não é exclusivo ao agronegócio, tampouco via isenções estritamente fiscais. Observa-se que até mesmo o Programa Nacional de Agricultura Familiar (PRONAF) na modalidade custeio da produção, preconiza o uso de agrotóxicos no desenho dos projetos que dão acesso ao programa, como uma espécie de condicionante 
Quadro 1

Desonerações tributárias para agrotóxicos no Brasil.

\begin{tabular}{|c|c|c|}
\hline & Leis/Decretos/Resolução & Definição \\
\hline \multirow[t]{3}{*}{ Imposto de Importação (II) } & $\begin{array}{l}\text { Lei no 8.032/1990 41, art. 2o, inciso II, } \\
\text { alínea 'h'. }\end{array}$ & $\begin{array}{c}\text { Dispõe sobre a isenção ou redução de impostos de importação, e dá } \\
\text { outras providências. }\end{array}$ \\
\hline & $\begin{array}{l}\text { Decreto no } 6.759 / 200942 \text {, art. } 136, \\
\text { inciso II, alínea 'h', arts. } 172,173,201, \\
\text { inciso VI - alíquota zero. }\end{array}$ & $\begin{array}{l}\text { Regulamenta a administração das atividades aduaneiras e a } \\
\text { fiscalização, o controle e a tributação das operações de comércio } \\
\text { exterior. }\end{array}$ \\
\hline & Resolução no 125/2016 22, Anexos I e II. & $\begin{array}{l}\text { Altera a Nomenclatura Comum do Mercosul (NCM) e estabelece as } \\
\text { alíquotas do imposto de importação que compõem a Tarifa Externa } \\
\text { Comum (TEC) e a Lista de Exceções à TEC. }\end{array}$ \\
\hline \multirow[t]{2}{*}{$\begin{array}{l}\text { Imposto sobre Produtos } \\
\text { Industrializados (IPI) }\end{array}$} & $\begin{array}{l}\text { Lei no 8.032/1990 41, art. 2o, inciso II, } \\
\text { alínea 'h' - isenção ou redução. }\end{array}$ & $\begin{array}{l}\text { Dispõe sobre a isenção ou redução de impostos de importação, e dá } \\
\text { outras providências. }\end{array}$ \\
\hline & Decreto no 8.950/2016 25, Anexo. & $\begin{array}{l}\text { Aprova a Tabela de Incidência do Imposto sobre Produtos } \\
\text { Industrializados (TIPI). }\end{array}$ \\
\hline \multirow{2}{*}{$\begin{array}{l}\text { Contribuição para o } \\
\text { Financiamento da Seguridade } \\
\text { Social (COFINS) e contribuição } \\
\text { para o Programa de Integração } \\
\text { Social e para o Programa de } \\
\text { Formação do Patrimônio do } \\
\text { Servidor Público (PIS/PASEP) }\end{array}$} & $\begin{array}{l}\text { Lei no } 10.925 / 200443 \text {, art. } 1 \text { o, inciso II - } \\
\text { alíquota zero. }\end{array}$ & $\begin{array}{l}\text { Reduz as alíquotas do PIS/PASEP e da COFINS incidentes na } \\
\text { importação e na comercialização do mercado interno de fertilizantes } \\
\text { e defensivos agropecuários e dá outras providências. }\end{array}$ \\
\hline & $\begin{array}{l}\text { Decreto no } 5.630 / 200544 \text {, art. 1으, } \\
\text { inciso II - alíquota zero. }\end{array}$ & $\begin{array}{c}\text { Dispõe sobre a redução a zero das alíquotas da Contribuição para o } \\
\text { PIS/Pasep e da Cofins incidentes na importação e na comercialização } \\
\text { no mercado interno de adubos, fertilizantes, defensivos } \\
\text { agropecuários e outros produtos. }\end{array}$ \\
\hline $\begin{array}{l}\text { Imposto sobre Circulação de } \\
\text { Mercadorias e Serviços (ICMS) }\end{array}$ & $\begin{array}{c}\text { Convênio ICMS no 100/1997 } 5 \text { do } \\
\text { Confaz - redução da base de cálculo } \\
\text { ou isenção. }\end{array}$ & $\begin{array}{l}\text { Reduz } 60 \% \text { da base de cálculo do ICMS nas } \\
\text { saídas interestaduais de agrotóxicos. }\end{array}$ \\
\hline
\end{tabular}

Fonte: adaptada de Tribunal de Contas da União 4.

nas análises dos bancos habilitados a operar com esta linha de crédito. Com isso, as chances de consumo de agrotóxicos são 52\% maiores para os beneficiários do PRONAF quando comparados aos não beneficiários, é o que revelam os dados do censo agropecuário de 2017 8,9.

O fato é que mesmo que haja benefícios sociais que sustentem tais desonerações, eles devem ser confrontados com os custos sociais dos agrotóxicos. Tais produtos são um caso clássico de externalidades negativas, o que significa que os danos à saúde e ambiente provocados pelo seu uso estão fora do sistema de trocas no mercado de compra e venda dos agrotóxicos. É um custo que está fora tanto da formação do preço dos agrotóxicos quanto dos produtos agrícolas que os utilizam e é externalizado para toda sociedade. Acabam aparecendo nas planilhas dos recursos gastos pelo Sistema Único de Saúde (SUS) para o tratamento de intoxicação e outas doenças crônicas relacionadas aos agrotóxicos, nos gastos públicos com fiscalização, registro, controle, dentre outras despesas com a regulação dessas substâncias perigosas.

Existem estudos internacionais sobre o tema e no Brasil há apenas estudos sobre a intoxicação aguda. O trabalho de Soares \& Porto ${ }^{10}$, que utiliza dados de uma pesquisa de agrotóxicos no Paraná, estima cenários de risco que o custo de intoxicação aguda pode variar entre 11 e 89 milhões de USD, dependendo das características dos produtores daquele estado ${ }^{10}$. Já na literatura internacional, o principal autor desse tipo de avaliação revela dados alarmantes desses custos para a economia americana a preços de 2013: USD 1,3 bilhão para custos com a saúde, incluindo cânceres; USD 4,2 bilhões para danos ambientais; e USD 3 bilhões de despesas com a regulação dessas substâncias perigosas 11.

Levando-se em consideração que existe um consumo similar de agrotóxicos ao dos Estados Unidos, instituições e produtores mais fragilizados para lidar com os riscos dessas "tecnologias" e produtos mais perigosos do ponto de vista ambiental e da saúde, é possível se esperar algo de dimensão semelhante para o Brasil. Isso torna-se ainda mais preocupante no atual momento do novo marco regulatório para os agrotóxicos, em que temos literalmente a porteira da fazenda aberta para essas substâncias perigosas e algumas banidas internacionalmente. 
Um outro ponto é que o produtor na hora de escolher um método de controle de pragas e doenças, tem preferencialmente optado pelos agrotóxicos às soluções mais sustentáveis, uma vez que os subsídios acabam distorcendo os custos dos diferentes métodos. Isso torna os agrotóxicos economicamente preferíveis e ao mesmo tempo concorrendo para um menor retorno esperado de uma possível transição agroecológica, desestimulando mais agricultores, portanto.

Devemos ressaltar a importância do artigo, tendo em vista que não há referências no país de estimativas dos valores renunciados com as isenções fiscais dadas aos agrotóxicos, e a sociedade brasileira necessita ter clareza e dimensão de quanto ela financia direta e indiretamente o uso dessas substâncias nocivas à saúde e ao ambiente, principalmente, num contexto de grave crise fiscal em que o Ministério da Economia está revendo inúmeros incentivos fiscais. Outro ponto é que, além do cálculo da desoneração fiscal com os agrotóxicos, discute-se principalmente o restabelecimento da função extrafiscal dos tributos, em que a taxação é um elemento de desestímulo à demanda dos agrotóxicos condizente com o princípio poluidor pagador, mitigando as externalidades negativas causadas pelos agrotóxicos, como as doenças e mortes evitáveis.

\section{Procedimentos metodológicos}

A metodologia decorre do aprimoramento da aplicada na dissertação de mestrado de Cunha 12, não apresenta conflito de interesse, de fato tem caráter impessoal e busca corroborar o campo da saúde pública. Um maior detalhamento dos procedimentos metodológicos pode também ser encontrado no relatório de pesquisa produzido pela Associação Brasileira de Saúde Coletivo (Abrasco) 13, por intermédio do Grupo de Trabalho de Saúde e Ambiente, que originou o presente artigo.

Seguimos a recomendação metodológica usada pelos países da Organização para a Cooperação e Desenvolvimento Econômico (OCDE), que estima a perda de arrecadação (ex post), e aplica a sistemática de incidência dos tributos sem considerar os benefícios fiscais concedidos 7 . Salienta-se que o resultado encontrado trata-se de uma estimativa, pois a precisão do valor desonerado depende de dados sigilosos e específicos de cada relação tributária. Desse modo, para um cálculo mais preciso seria necessário o esforço conjunto das fazendas estaduais e do Distrito Federal em cooperação com a Receita Federal do Brasil.

A primeira etapa metodológica contou com a reunião de uma extensa e complexa pesquisa bibliográfica sobre a documentação da legislação tributária das 27 Unidades da Federação (UF), e que possibilitaram a fixação das alíquotas vigentes que seriam aplicadas sem incentivos fiscais. Em seguida, os quantitativos das desonerações fiscais foram estimados com base nos dados do último Censo Agropecuário de 20178 e dos dados de comércio exterior 14 para se estimar a desoneração do imposto sobre as importações. O valor das operações de importação dos agrotóxicos foi determinado por meio dos valores importados dos produtos classificados no código SH4 3808, deduzidos os desinfetantes.

O Censo Agropecuário foi eleito como a melhor fonte de dados para se estimar a desoneração fiscal, pois representa o valor agregado total aos agrotóxicos durante seu ciclo de vida, o que corresponde à despesa do produtor rural com este produto. Isso ocorre devido a não cumulatividade do IPI e do ICMS, ou seja, ambos incidem sobre o valor adicionado das operações de industrialização e comercialização com agrotóxicos, respectivamente, além disso, o PIS/PASEP e a COFINS também podem ser apurados dessa maneira. Já o imposto sobre importação incide sobre o valor das importações. Desse modo, dados do Instituto Brasileiro do Meio Ambiente e dos Recursos Naturais Renováveis (IBAMA), da Pesquisa Industrial Anual (Instituto Brasileiro de Geografia e Estatística - IBGE), que consideram apenas as operações entre indústria e atacadistas, não representam o valor final das operações de venda dos agrotóxicos, tampouco o de importação.

\section{Desoneração do ICMS}

O ICMS é um imposto indireto de competência estadual e incide sobre a circulação de mercadorias, bens e serviços interestaduais e intermunicipais de transporte e de comunicação (Art. 155, inciso II 6). Ele deve ser não cumulativo e pode ser seletivo de acordo com a essencialidade do bem ou serviço objeto de sua incidência (Art. 155, \$2 o incisos I e III6). Devido a não cumulatividade obrigatória, o 
contribuinte recolhe o tributo apenas sobre o valor adicionado na operação posterior compensandose do crédito referente à operação anterior por meio da sistemática de débitos e créditos.

A legislação tributária que regulamenta a sistemática de aplicação do ICMS foi consultada com a finalidade de embasar tecnicamente o cálculo da renúncia fiscal. Dentre as informações relevantes, destacamos: os tipos de operação que podem envolver os agrotóxicos e a maneira de calcular o montante desonerado.

É notório que as operações de comercialização de agrotóxicos podem ser internas, interestaduais ou de importação 15. Sendo que as alíquotas de importação e internas são as mesmas, em geral, já as interestaduais variam conforme a origem e o destino das mercadorias. Nesta pesquisa, admitiu-se que a despesa declarada ao Censo Agropecuário correspondem a operações internas. Desse modo, essa hipótese considera que a última transação com os agrotóxicos antes de seu uso ocorreu dentro da unidade federativa onde ele foi consumido.

Observa-se que o ICMS integra sua própria base de cálculo, assim, sua incidência ocorre por dentro (Art.13, \$1o, inciso I 15). Com isso, o valor da mercadoria corresponde à porcentagem da base de cálculo deduzida a alíquota de incidência do ICMS, conforme os seguintes cálculos:

Cálculo 1 - Base de cálculo da isenção do ICMS:

$$
\text { Base de cálculo }=\frac{\text { Valor da operação }}{(1-\text { alíquota ICMS })}
$$

Cálculo 2 - Redução da base de cálculo do ICMS em 60\%:

$$
\text { Base de cálculo }=\frac{\text { Valor da operação }}{(1-\text { alíquota ICMS })} \times 0,6
$$

Com a finalidade de estimar a renúncia sobre os agrotóxicos, as alíquotas aplicáveis nas operações internas e as respetivas bases legais vigentes em 2017 foram sistematizadas no Quadro 2.

Na maior parte das UF a alíquota de ICMS aplicável aos agrotóxicos é a geral, de modo que a maior especificidade encontrada foi com o uso de termos como "insumos agropecuários". Nota-se que a maioria das UF concede isenção nas operações internas com agrotóxicos e todas reduzem a base de cálculo em $60 \%$ nas operações interestaduais, conforme a cláusula primeira do Convênio ICMS no 100/1997 5.

O convênio que autoriza a concessão dos incentivos fiscais aos agrotóxicos é considerado como de tempo determinado, entretanto, na prática funciona como se fosse por tempo indeterminado, devido às suas constantes prorrogações.

\section{Desoneração das contribuições sociais (PIS/PASEP e COFINS)}

As contribuições sociais são uma espécie tributária de notória relevância, pois sua arrecadação é vinculada, em regra, ao financiamento da seguridade social (Caput e incisos do art. 195 6). Dentre elas, o PIS/PASEP e a COFINS incidem sobre a receita bruta das vendas e na importação de agrotóxicos.

O contribuinte pode apurar o montante devido por meio de dois regimes: o não cumulativo 16,17 e o cumulativo 18,19. O regime não cumulativo tem alíquotas de 1,65\% 16 e 7,6\% 17, já no cumulativo as alíquotas são de $0,65 \% 18$ e $3 \%$ 19, para o PIS/PASEP e a COFINS, respectivamente. A não cumulatividade implica a incidência do tributo sobre o valor agregado, por meio do crédito gerado nas operações anteriores, já no regime cumulativo há a incidência sobre o valor integral da operação, sem a possibilidade de dedução do montante anterior recolhido. O que determina o regime de apuração é a forma da pessoa jurídica que é contribuinte conforme o Art. 8o da Lei no 10.637/2002 16 e o Art. 10 da Lei no 10.833/2003 17.

Nas operações de importação as alíquotas são de 2,1\% e 9,65\% de PIS/PASEP e da COFINS, respectivamente 20 . No caso desse tipo de operação não há diferença de regime de apuração, no entanto, na operação posterior o contribuinte poderá se creditar ou não o montante recolhido na importação a depender do regime a que está sujeito.

O valor renunciado desses dois tributos já foi estimado pela Receita Federal para o ano de 2017, devido ao requerimento do TCU para a realização de relatório de auditoria 4 , já que esse valor não estava apresentado separadamente nos demonstrativos de gastos tributários da União daquele ano. 
Quadro 2

Tipo de renúncia fiscal e alíquota que seria aplicável.

\begin{tabular}{|c|c|c|c|}
\hline UF & $\begin{array}{l}\text { Alíquota vigente } \\
\text { em } 2017(\%)\end{array}$ & $\begin{array}{l}\text { Tipo de renúncia em } \\
\text { operações internas }\end{array}$ & Base legal da renúncia \\
\hline Acre & 17,0 & Isenção & Decreto no 921 de 1998. \\
\hline Alagoas & 17,0 & Isenção & Convênio ICMS no 100/1997 e alterações. \\
\hline Bahia & 18,0 & Isenção & Art. 20 do Decreto no 5.444 de 1996. \\
\hline Ceará & 18,0 & Isenção & Art. 6, LXXIII, “a” do Decreto no 24.569 de 1997. \\
\hline Distrito Federal & 18,0 & Isenção & Convênio ICMS no 100/1997. \\
\hline Espirito Santo & 17,0 & Isenção & Art. 5, LV do Decreto no 1.090-R, de 25 de outubro de 2002. \\
\hline Goiás & 7,0 & Isenção & Art. 7, XXV, “a” do anexo IX do Decreto no 4.852, de 1997. \\
\hline Mato Grosso & 17,0 & Isenção & Art. 115 do Decreto no 2.212 de 2014. \\
\hline Mato Grosso do Sul & 17,0 & Isenção & Art. 29 do anexo I do Decreto no 9.203, de 1998. \\
\hline Minas Gerais & 18,0 & Isenção & Item 4 da parte I do anexo I do Decreto no 43.080 de 2002. \\
\hline Pará & 17,0 & Isenção & Art. 64, "a" do anexo II do Decreto no 4.676 de 2001. \\
\hline Paraíba & 18,0 & Isenção & Art. 6, XIII, “a”, do Decreto no 18.930 de 1997. \\
\hline Pernambuco & 18,0 & Isenção & Art. 114 do anexo 78 do Decreto no 43.901 de 2016. \\
\hline Piauí & 17,0 & Isenção & $\begin{array}{c}\text { Art. 44, XXVI, "a" do Decreto no } 3.500 \text { de } 2008 \text { - Convênio ICMS no 100/1997 } \\
\text { e alterações. }\end{array}$ \\
\hline Rio de Janeiro & 20,0 & Isenção & Convênio ICMS no 100/1997 e alterações. \\
\hline $\begin{array}{l}\text { Rio Grande do } \\
\text { Norte }\end{array}$ & 17,0 & Isenção & Art. 12 do Decreto no 28.606 de 2018 . \\
\hline Rio Grande do Sul & 18,0 & Isenção & Art. 9, VIII, “a” do Decreto no 37.699 de 1996. \\
\hline Rondônia & 17,5 & Isenção & Tabela II do anexo I do Decreto no 8.321 de 1998. \\
\hline Roraima & 12,0 & Isenção & Art. 1, LXVII e art. 2, IX do anexo I do Decreto no 4.335 de 2001. \\
\hline Santa Catarina & 17,0 & Isenção & $\begin{array}{l}\text { Art. } 29 \text { (isenção) e art. } 30 \text { (redução da base de cálculo) do anexo } 2 \text { do } \\
\text { RICMS/SC-01. }\end{array}$ \\
\hline São Paulo & 18,0 & Isenção & Convênio ICMS no 100/1997 e alterações. \\
\hline Sergipe & 18,0 & Isenção & $\begin{array}{l}\text { (redução da base de cálculo) Item } 7 \text { do anexo II do Decreto no 21.400/2002 } \\
\text { - (isenção) Item 42, I da Tabelas II do anexo I do Decreto no 21.400/2002. }\end{array}$ \\
\hline Tocantins & 18,0 & Isenção & Art. 5, XI do Decreto no 2.912 de 29 de dezembro de 2006. \\
\hline Amapá & 18,0 & \multirow{4}{*}{$\begin{array}{l}\text { Redução da base de } \\
\text { cálculo em } 60 \% \text { para } \\
\text { cada UF }\end{array}$} & Decreto no 2.892 de 2001. \\
\hline Amazonas & 18,0 & & Art. 13, § 25 do Decreto no 20.686 de 1999. \\
\hline Maranhão & 18,0 & & Art. 2, "a" do anexo 1.4 do Decreto no 19.714 de 2003. \\
\hline Paraná & 18,0 & & Item 15, posição 11 do anexo VI do RICMS-PR. \\
\hline
\end{tabular}

ICMS: Imposto sobre Circulação de Mercadorias e Serviços; UF: Unidades da Federação.

Fonte: Cunha 12, com base nas legislações estaduais e distrital sobre ICMS.

Portanto, para a consolidação do resultado a estimativa da Fazenda Nacional foi a utilizada, tendo em vista que é o número que mais se aproxima da realidade considerando que ela tem acesso aos dados dos contribuintes e a suas particularidades na apuração do montante devido.

\section{Desoneração do Imposto de Importação (II)}

É notório que o Brasil faz parte do Mercosul e devido a isto está sujeito a algumas normas de comércio exterior. Dentre elas, destaca-se para fins de estimativa da desoneração fiscal do imposto de importação sobre os agrotóxicos a Lista Exceções à Tarifa Externa Comum (Letec), que prevê produtos que poderão ter alíquotas de importação diferentes da Tarifa Externa Comum (Tec) 21. 
Até 2021, o Brasil pode incluir na Letec cem códigos da Nomenclatura Comum do Mercosul (NCM) 22. No que diz respeito aos agrotóxicos em 2017, quatro códigos NCM estão presentes na Letec e suas alíquotas foram reduzidas a zero 22, conforme a Tabela 1.

A lista de exceções pode ser revisada periodicamente, e apesar da norma que dispõe sobre os códigos da lista ser de 2016 22, estes códigos estão na Letec desde 2007 23. Baseando-se na comparação do total de agrotóxicos importados no período em relação aos que se classificam nos códigos da Letec, observa-se que estes representam $77,2 \%$ do total importado, fato que evidencia o poder extrafiscal do imposto de importação. Para se estimar o montante desonerado aplicou-se as alíquotas da tarifa externa comum correspondentes ao valor importado dos respectivos códigos, como se estes não estivessem incluídos na Letec.

\section{Desoneração do Imposto de Produção Industrial (IPI)}

O IPI incide sobre a industrialização, conforme definido no regulamento 24, e sobre a importação de produtos industrializados. Ele deve ser seletivo de acordo com a essencialidade do produto e não cumulativo, de modo que incide apenas sobre o valor agregado às operações anteriores (Art. 153, $₫$ 3o, incisos I e II 5).

A Tabela de Incidência do Imposto sobre Produtos Industrializados (TIPI) é um decreto que estabelece a lista de produtos com base na nomenclatura comum do Mercosul que são objeto de incidência do IPI e define as respectivas alíquotas 25 .

Todos os códigos que se referem aos agrotóxicos apresentam alíquota zero. Nota-se que os únicos produtos classificados no grupo 3808 que têm alíquota maior que zero são os desinfetantes 25 .

Desse modo, com a finalidade de se viabilizar a estimativa da desoneração fiscal concedida à industrialização de agrotóxicos utilizou-se uma alíquota arbitrada de 5\%, pois é a menor alíquota aplicada ao grupo 3808 diferente de zero. Portanto, com base na aplicação dessa sobre o montante das despesas com agrotóxicos declaradas ao Censo Agropecuário de 2017 obteve-se a desoneração estimada desse imposto sobre os agrotóxicos.

\section{Resultados}

Nesta seção, são apresentados os resultados consolidados por tributo e respectivo ente competente. Como as competências tributárias referem-se a diferentes esferas de governo, os resultados foram discriminados conforme estas e consolidados em nível de país. Desse modo, a Tabela 2 está disposta em estados e no Distrito Federal, consolidada neste nível; discriminada por tributo no nível da União; e consolidada no Brasil.

\section{Tabela 1}

Lista de exceções à tarifa externa comum do Mercosul.

\begin{tabular}{lccc}
\hline $\begin{array}{l}\text { Código da nomenclatura } \\
\text { comum do Mercosul }\end{array}$ & Descrição & $\begin{array}{c}\text { Tarifa externa } \\
\text { comum (\%) }\end{array}$ & $\begin{array}{c}\text { Lista de exceções } \\
\text { à tarifa externa } \\
\text { comum - Brasil (\%) }\end{array}$ \\
\hline 3808.91 .91 & $\begin{array}{c}\text { Inseticidas à base de acefato ou de } \\
\text { Bacillus thuringiensis }\end{array}$ & 14 & 0 \\
3808.91 .99 & Outros inseticidas & 8 & 0 \\
3808.92 .99 & Outros fungicidas & 8 & 0 \\
3808.93 .29 & $\begin{array}{c}\text { Outros herbicidas, inibidores de } \\
\text { germinação e reguladores de } \\
\text { crescimento das plantas }\end{array}$ & 8 & 0 \\
\hline
\end{tabular}

Fonte: relatório de auditoria do Tribunal de Contas da União 4 e Resolução no 125 22, anexos I e II. 
Tabela 2

Benefícios fiscais estaduais e distrital aos agrotóxicos em milhões de Reais em 2017.

\begin{tabular}{|c|c|}
\hline UF & Renúncia de ICMS (milhões de Reais) \\
\hline Acre & 4,21 \\
\hline Alagoas & 30,70 \\
\hline Bahia & 454,48 \\
\hline Ceará & 7,62 \\
\hline Distrito Federal & 15,22 \\
\hline Espírito Santo & 42,57 \\
\hline Goiás & 179,95 \\
\hline Mato Grosso & 1321,44 \\
\hline Mato Grosso do Sul & 391,21 \\
\hline Minas Gerais & 696,52 \\
\hline Pará & 66,29 \\
\hline Paraíba & 8,04 \\
\hline Pernambuco & 37,97 \\
\hline Piauí & 81,16 \\
\hline Rio de Janeiro & 14,34 \\
\hline Rio Grande do Norte & 12,52 \\
\hline Rio Grande do Sul & 945,94 \\
\hline Rondônia & 61,05 \\
\hline Roraima & 2,94 \\
\hline Santa Catarina & 171,79 \\
\hline São Paulo & 953,90 \\
\hline Sergipe & 6,45 \\
\hline Tocantins & 107,64 \\
\hline Amapá & 0,65 \\
\hline Amazonas & 1,96 \\
\hline Maranhão & 64,02 \\
\hline Paraná & 542,05 \\
\hline Total & $6.222,64$ \\
\hline
\end{tabular}

ICMS: Imposto sobre Circulação de Mercadorias e Serviços; UF: Unidades da Federação.

Fonte: elaborado pelo autor com base nos dados do Censo Agropecuário 20178 e na legislação tributária federal e estadual.

A Tabela 3 consolida os resultados das desonerações com agrotóxicos no Brasil, segundo os tributos e suas respectivas competências tributárias. Os benefícios fiscais concedidos aos agrotóxicos em 2017 chegam a quase BRL 10 bilhões, sendo que o ICMS foi o tributo responsável pelo maior montante desonerado em 2017 (63\%), seguido do IPI (16\%), as contribuições sociais PIS/PASEP e COFINS (16\%) e o II, com $5 \%$.

Na proposta orçamentária da União para o exercício de 2019 foram previstos BRL 26,1 bilhões para a função orçamentária da agricultura 26. Dessa forma, os BRL 3,6 bilhões da desoneração que impactam diretamente o orçamento federal representam quase 14\% do orçamento da agricultura.

Conforme a Receita Federal 27, a arrecadação total de PIS/PASEP e COFINS, segunda maior receita tributária da União, foi de BRL 281 bilhões em 2017. Desse modo, o gasto tributário de 2017 associado a essas contribuições sociais sobre os agrotóxicos representa pouco mais de $1 \%$ do total arrecadado. No entanto, quando comparamos o valor desse gasto tributário ao orçamento da Agência Nacional de Vigilância Sanitária, BRL 920 milhões em 2017 28, observamos que aquele representa mais de três vezes este valor, o que evidencia a materialidade do mesmo. 
Tabela 3

Consolidação dos resultados de acordo com a competência tributária.

\begin{tabular}{lccc}
\hline Competência tributária & Tributos & $\begin{array}{c}\text { Desoneração } \\
\text { (bilhões de Reais) }\end{array}$ & Distribuição (\%) \\
\hline União & PIS/PASEP e COFINS & 1,53 & 16 \\
& IPI & 1,62 & 16 \\
Estados e Distrito Federal & II & 0,47 & 5 \\
Brasil (Total) & ICMS & 6,22 & 63 \\
\hline
\end{tabular}

COFINS: Contribuição para o Financiamento da Seguridade Social; ICMS: Imposto sobre Circulação de Mercadorias e Serviços; II: Imposto de Importação; IPI: Imposto sobre Produtos Industrializados; PASEP: Programa de Formação do Patrimônio do Servidor Público; PIS: Programa de Integração Social.

Fonte: elaborado pelo autor com base nos dados do Censo Agropecuário 20178 e na legislação tributária federal e estadual.

Quanto aos estados, é notório que eles estão passando por crises fiscais agudas, vide os acordos de austeridade celebrados entres estes e a União. Dessa forma, esses incentivos fiscais impactam fortemente os orçamentos estaduais. Como exemplo ilustrativo, o déficit orçamentário do Rio Grande do Sul em 2017, que foi de BRL 1.668.735.918,34 29 e a renúncia fiscal de ICMS em 2017 foi de BRL 945 milhões. Logo, a renúncia daquele ano representa cerca de 56,7\% do déficit do exercício de 2017 desse estado. Os estados de Mato Grosso e São Paulo foram os que mais deixaram de arrecadar com ICMS para seus cofres.

\section{Discussão}

Os resultados encontrados mostram que em plena crise fiscal confere-se benefícios que chegam a custar aos cofres públicos quase BRL 10 bilhões. Considerando-se ainda os custos sociais dos agrotóxicos externalizados nas despesas orçamentárias da seguridade social, notadamente do SUS com os casos de intoxicação aguda e demais problemas crônicos de saúde, não haveria sem sombra de dúvidas "benefícios sociais" que justifiquem tal renúncia e o incentivo ao uso dessas substâncias.

Conforme pesquisa realizada pelo Centro de Estudos Avançados em Economia Aplicada (Cepea) 30, a ausência de controle afetaria a produtividade agrícola, mas esta queda seria amortecida em parte pelo aumento da receita do produtor em função do aumento do preço na cotação internacional e da redução dos custos de produção, tendo em vista a não realização de despesas com a compra de agrotóxicos. No caso da soja e sua principal praga, a ferrugem asiática, uma ausência total do controle ocasionaria uma perda de receita de $8,5 \%$ e uma redução da despesa com a produção de quase $4 \%$, amortecendo o impacto econômico negativo na hipótese da ausência total do emprego de fungicidas.

Em 2017, o Sindicato Nacional da Indústria para Defesa do Vegetal (SINDVEG) divulgou um relatório com cenários de impacto nos preços dos alimentos com a ausência de subsídios aos agrotóxicos 31. O resultado deles demonstrou um aumento na carga tributária de BRL 8,3 bilhões para 2016, sendo que não consideraram a desoneração do imposto de importação e adotaram hipóteses metodológicas distintas da deste artigo para mensurar a desoneração dos demais tributos 31 . A argumentação dos autores parte da premissa de que a carga tributária tira eficiência do setor e que isto impactaria a inflação e pioraria o desempenho econômico do Brasil 31.

Observa-se que esse relatório do SINDVEG atribui uma relação direta da carga tributária com o aumento dos preços agrícolas, porém, a relação entre a oferta e a demanda depende de outros fatores e de como este gasto tributário pode ser direcionado. A receita tributária gerada poderia ser utilizada, por exemplo, para uma política pública de incentivo à transição agroecológica e assim frear o efeito inflacionário apontado pelo relatório. 
Projetar cenários de impacto sobre os preços dos produtos agrícolas devido ao aumento da carga tributária sobre agrotóxicos e associá-los diretamente ao aumento da despesa dos produtores é, sem dúvida, desconsiderar os efeitos de médio e longo prazos que esta medida tende a exercer sobre a demanda dos agrotóxicos. Ou seja, é desconsiderar o potencial da função extrafiscal dos tributos de desestimular o consumo dessa substância de alta periculosidade, não levando em conta também os efeitos monetários da redução das externalidades associadas ao uso dos agrotóxicos e que já foram destacados neste texto 11,12 .

Deve-se ressaltar que a distorção da eficiência econômica dos agrotóxicos gerada pelo subsídio fiscal prejudica a concorrência e o desenvolvimento de outros modelos operacionais para a agricultura. Portanto, a tributação dos agrotóxicos tem potencial de alterar a tomada de decisão de empregar agrotóxicos ou outro método de controle.

Apesar disso, devido à "dependência" da produção agrícola convencional aos agrotóxicos, esperase que no curto prazo o efeito na demanda por eles não seja tão afetado pelo aumento do preço. Isso demonstra a baixa sensibilidade de alterações na demanda em função das mudanças nos preços dos agrotóxicos, ou seja, uma baixa elasticidade no preço da demanda. Isso se dá principalmente no cultivo da produção em larga escala de monoculturas, cujo desequilíbrio ecológico exige o uso de agrotóxicos.

Todavia, há de se esperar mudanças no comportamento da demanda dos agrotóxicos no médio e longo prazos como aconteceu com o cigarro. Observa-se que a elasticidade no preço da demanda não é estática; estimativas de Becker et al. 32 para os Estados Unidos apontam para uma elasticidade de curto prazo de -0,40 e uma elasticidade de longo prazo de - $-0,76$, ou seja, aumentos de $1 \%$ no preço do cigarro reduziria o consumo em $0,40 \%$ e $0,76 \%$ no curto e longo prazos, respectivamente. Gospodinov \& Irvine 33 estimam a elasticidade de curto prazo para o Canadá em -0,11 e a elasticidade de longo prazo em -0,31. Dessa forma, a mudança tardia na percepção e no comportamento dos consumidores seria um movimento positivo para a transição agroecológica, que exige um período de no mínimo três a cinco anos.

Desse modo, uma possível ausência das desonerações sobre os agrotóxicos geraria no médio prazo uma redução da demanda por agrotóxicos e a diminuição dos custos sociais externalizados pelo seu uso. Esses impactos poderiam ser ainda mais eficientes se a taxação estivesse associada ao risco do produto, como em alguns países (Canadá, Noruega, Suécia, Bélgica, Dinamarca, França, Itália, Holanda, dentre outros) ${ }^{34}$. A Dinamarca taxa de acordo com o potencial toxicológico, carcinogênico e de impacto ambiental da substância ativa ${ }^{34}$. Na França e em outros países europeus, o montante arrecado é destinado às políticas de transição agroecológica 34. Já no Brasil, esse mecanismo funciona às avessas.

Observa-se que de acordo com os dados do IBAMA 35, apenas seis produtos agrícolas correspondem a $85 \%$ das vendas dos agrotóxicos no Brasil (soja, cana-de-açúcar, algodão, milho safrinha, milho, trigo e café) e são commodities agrícolas. Nesses casos, os produtores são tomadores de preços e não formadores, ou seja, seus preços são ditados pelo mercado internacional e não pela formação de custos no mercado local. Apesar disso, um aumento no custo de produção pode desestimular a oferta desses produtos em função do menor lucro do produtor e de impactar os preços internacionais no médio prazo.

Por outro lado, no curto prazo espera-se um impacto sobre as olericulturas que utilizam bastante agrotóxicos. Já as verduras têm potencial para serem produzidas com técnicas sustentáveis, mas dependem de um conjunto de políticas públicas que estimulem a transição agroecológica, como a implantação dos sistemas participativos de garantias e controle social da produção orgânica, de forma a desonerar e flexibilizar o custo da certificação do produtor orgânico. Provavelmente como resultado há o crescimento de quase $1.000 \%$ nos estabelecimentos certificados como orgânicos quando comparamos os dois censos agropecuários, de 2006 contra 20178.

Desse modo, a tributação ajudaria a acabar com a distorção econômica na preferência dos agricultores em utilizar métodos de controle convencionais em vez de métodos e práticas aliados à produção orgânica e agroecológica. Dessa maneira, fortalecer práticas agrícolas alternativas mais saudáveis e sustentáveis poderia fazer com que o Brasil deixasse de ser um paraíso da poluição do mercado internacional 36 . 
Além disso, ressalta-se que os instrumentos usados para regular os agrotóxicos no Brasil são pautados em ações de comando e controle, padrões que definem um limite tolerável de dano ${ }^{37}$. Dessa forma, o poder fiscalizatório e regulador do Estado influencia a tomada de decisão do potencial poluidor, pois a capacidade de aplicação da lei determinará o custo-benefício em infringir ou não a legislação. Assim, a tributação aos agrotóxicos mostra-se como alternativa à regulação já que é tanto uma medida fiscal, que traria receita ao erário, como extrafiscal já que reduziria seu uso e os custos sociais decorrentes.

Independentemente da abordagem a ser adotada para o fim dos incentivos fiscais aos agrotóxicos, é imprescindível o mapeamento dos atores envolvidos que têm interesse no agronegócio e seu respectivo poder de influência nos processos de tomada de decisão.

O mercado de agrotóxicos é formado por dois tipos de empresas, as integradas e as especializadas. As primeiras são as detentoras da maior fatia do mercado, de maneira que cerca de dez empresas controlavam aproximadamente $98 \%$ das vendas mundiais em 2004 38; no Brasil dez empresas controlam mais de $70 \%$ do mercado interno de agrotóxicos 39 . Esse fenômeno é explicado devido à estratégia competitiva dessas empresas, que consiste na pesquisa e desenvolvimento de novos produtos ativos e na criação de patentes. Já as especializadas trabalham com produtos equivalentes, que são aqueles que tiveram suas patentes vencidas e que podem ser reproduzidos livremente 40 . Portanto, a hegemonia econômica representada pela participação de mercado altamente concentrado, no mundo e no Brasil, demonstra que os incentivos fiscais aos agrotóxicos geram concentração de renda.

As empresas integradas são estratégicas na configuração atual do comércio de agrotóxicos, de modo que a sua aderência a uma nova estrutura operacional do agronegócio poderia determinar o sucesso econômico e político na mitigação ou até mesmo eliminação do uso de agrotóxicos, já que elas têm como estratégia competitiva a diferenciação de produtos 40 . Isso ocorre devido ao rápido ciclo de vida dos agrotóxicos e à resistência dos organismos alvo. Além disso, as externalidades negativas sobre o meio ambiente e a saúde pressionam novas formas de atuação. Dentre elas, as empresas inovadoras buscam desenvolver novas moléculas que apresentam menores efeitos residuais e baixa toxicidade 40 .

\section{Considerações finais}

É consenso que os instrumentos econômicos devem desincentivar o uso de substâncias perigosas. Dentre tantos fatores importantes, destacam-se: a função extrafiscal dos tributos e os efeitos dos incentivos fiscais aos agrotóxicos no setor agrícola.

A literatura visitada demonstra que as externalidades negativas devem ser mitigadas pelos instrumentos econômicos. Dessa maneira, diversos países usam a função extrafiscal tributária para desestimular o uso de agrotóxicos.

Apesar da experiência internacional, a política brasileira de incentivo fiscal aos agrotóxicos vai na contramão das ações de regulação dos problemas sanitários e ambientais. Assim, os subsídios aos agrotóxicos distorcem a eficiência econômica de seu uso, fazendo com que o método agrícola convencional seja mais interessante financeiramente do que outros como o agroecológico.

Dessa forma, conclui-se que o modelo fiscal influencia o modelo operacional da agricultura convencional. Portanto, é urgente a adoção de um novo modelo que estimule a formulação de substâncias com menores efeitos nocivos e com potencial de mitigar ou mesmo eliminar o uso de agrotóxicos e assim fortalecer as práticas agrícolas sustentáveis. 


\section{Colaboradores}

L. N. Cunha desenvolveu a metodologia, calculou os resultados e sistematizou os conhecimentos normativos necessários. W. L. Soares contribuiu na revisão metodológica e com a construção do texto. Ambos aprovaram a versão final para publicação.

\section{Informações adicionais}

ORCID: Lucas Neves da Cunha (0000-0002-4442613X); Wagner Lopes Soares (0000-0001-79937418).

\section{Agradecimentos}

Este trabalho foi parcialmente financiado pelo Instituto Ibirapitanga em parceria com a Associação Brasileira de Saúde Coletiva.

\section{Referências}

1. Bull D, Hathaway D. Pragas e venenos: agrotóxicos no Brasil e no terceiro mundo. Petrópolis: Vozes Editora; 1986.

2. Food and Agriculture Organization; International Fertilizer Industry Association. Fertilizer strategies. Rome: Food and Agriculture Organization; 1999.

3. Seligman M, Mello F. Lobby desvendado democracia, políticas públicas e corrupção no Brasil contemporâneo. Rio de Janeiro: Editora Record; 2018.

4. Tribunal de Contas da União. Relatório de auditoria. Avaliação da preparação do governo brasileiro para implementar e monitorar os objetivos de desenvolvimento sustentável (ODS). Compromisso assumido pelo Brasil junto à ONU. Identificação de oportunidades de melhoria. https://tcu.jusbrasil.com. br/jurisprudencia/566686362/relatorio-deauditoria-ra-ra-2942720177?ref=serp (acessado em 05/Jul/2019).

5. Conselho Nacional de Política Fazendária. Convênio ICMS no 100 de 04 de novembro de 1997. Reduz a base de cálculo do ICMS nas saídas dos insumos agropecuários que especifica, e dá outras providências. Diário Oficial da União 1997; 6 nov.

6. Senado Federal. Constituição da República Federativa do Brasil. Brasília: Senado Federal; 1988.

7. Secretaria da Receita Federal, Ministério da Fazenda. Demonstrativo dos gastos tributários de 2019. Brasília: Ministério da Fazenda; 2019.

8. Instituto Brasileiro de Geografia e Estatística. Censo agropecuário, 2017. https://sidra.ibge. gov.br/pesquisa/censo-agropecuario/censoagropecuario-2017 (acessado em 30/Out/ 2019).

9. Soares WL. Agrotóxicos no Brasil: reflexões a partir dos Censos Agropecuários. In: Anais do Encontro Sociedade Brasileira de Economia Ecológica. https://www.ecoeco2019. sinteseeventos.com.br/arquivo/downloadpublic?q=YToyOntzOjY6InBhcmFtcyI7 czozNDoiYToxOntzOjEwOiJJRF9BUlFVSVZPIjtzOjM6IjMwOSI7fSI7czoxOiJoIjtzOjMyOiI4YTI3MTI5NThjZmNmZjkwNWIzYTY5OTA1N2I2MzRiYSI7fQ\%3D\%3D (acessado em 10/ Out/2019).

10. Soares WL, Porto MF. Estimating the social cost of pesticide use: an assessment from acute poisoning in Brazil. Ecological Economics 2009; 68:2721-8.

11. Pimentel D. Environmental and economic costs of the application of pesticides primarily in the United States. In: Peshin R, Dhawan $\mathrm{Ak}$, editors. Integrated pest management: innovation-development process. Dordrecht: Springer; 2009. p. 89-111. 
12. Cunha LN. Agricultura na contramão: agronegócio, incentivos fiscais e a política de regulação dos agrotóxicos [Dissertação de Mestrado]. Seropédica: Universidade Federal Rural do Rio de Janeiro; 2019.

13. Soares WL, Cunha LN, Porto MFS. Uma política fiscal a agrotóxicos no Brasil é injustificável e insustentável. Rio de Janeiro: Associação Brasileira de Saúde Coletiva; 2020.

14. Comércio Exterior e Serviços, Ministério da Indústria. Base de dados de comércio exterior. http://comexstat.mdic.gov.br/pt/home (acessado em 20/Jan/2019).

15. Brasil. Lei Complementar no 87, de 13 de setembro de 1996. Dispõe sobre o imposto dos Estados e do Distrito Federal sobre operações relativas à circulação de mercadorias e sobre prestações de serviços de transporte interestadual e intermunicipal e de comunicação, e dá outras providências. Diário Oficial da União 1996; 16 set.

16. Brasil. Lei no 10.637 , de 30 de dezembro de 2002. Dispõe sobre a não-cumulatividade na cobrança da contribuição para os Programas de Integração Social (PIS) e de Formação do Patrimônio do Servidor Público (Pasep), nos casos que específica; sobre o pagamento e o parcelamento de débitos tributários federais, a compensação de créditos fiscais, a declaração de inaptidão de pessoas jurídicas, a legislação aduaneira, e dá outras providências. Diário Oficial da União 2002; 31 dez.

17. Brasil. Lei no 10.833 , de 29 de dezembro de 2003. Altera a Legislação Tributária Federal e dá outras providências. Diário Oficial da União 2003; $30 \mathrm{dez}$.

18. Brasil. Lei no 9.715 , de 25 de novembro de 1998. Dispõe sobre as contribuições para os Programas de Integração Social e de Formação do Patrimônio do Servidor Público - PIS/ PASEP, e dá outras providências. Diário Oficial da União 1998; 26 nov.

19. Brasil. Lei no 9.718 , de 27 de novembro de 1998. Altera a Legislação Tributária Federal. Diário Oficial da União 1998; 28 nov.

20. Brasil. Lei no 10.865 , de 30 de abril de 2004. Dispõe sobre a Contribuição para os Programas de Integração Social e de Formação do Patrimônio do Servidor Público e a Contribuição para o Financiamento da Seguridade Social incidentes sobre a importação de bens e serviços e dá outras providências. Diário Oficial da União 2004; 30 abr.

21. Mercosul. Conselho do Mercado Comum. Decisão no 26/2015. Modificação da decisão 58/2010. https://normas.mercosur.int/public/ normativas/3159 (acessado em 30/Out/2019).

22. Câmara de Comércio Exterior. Resolução no 125, de 15 de dezembro de 2016. Altera a Nomenclatura Comum do Mercosul - NCM e a Tarifa Externa Comum - TEC, a Lista de Exceções à TEC e a Lista de Exceções de Bens de Informática e Telecomunicações - BIT para adaptação às modificações do Sistema Harmonizado (SH-2017). Diário Oficial da União 2016; 16 dez.
23. Câmara de Comércio Exterior. Resolução no 71 , de 20 de dezembro de 2007. Altera, na forma dos Anexos I e II a esta Resolução, a Nomenclatura Comum do MERCOSUL - NCM e as alíquotas do Imposto de Importação que compõem a Tarifa Externa Comum - TEC, de que trata o Anexo I da Resolução Camex 43, de 22 de dezembro de 2006. Diário Oficial da União 2007; 24 dez.

24. Brasil. Decreto no 7.212 de 2010. Regulamenta a cobrança, fiscalização, arrecadação e administração do Imposto sobre Produtos Industrializados - IPI. Diário Oficial da União 2007; 16 jun.

25. Brasil. Decreto no 8.950 , de 29 de dezembro de 2016. Aprova a Tabela de Incidência do Imposto sobre Produtos Industrializados - TIPI. Diário Oficial da União 2016; $30 \mathrm{dez}$.

26. Presidência da República. Mensagem 483. Proposta orçamentária de 2019. https://www2. camara.leg.br/orcamento-da-uniao/leis-orca mentarias/loa/2019/tramitacao/proposta-do -poder-executivo (acessado em 05/Jul/2019).

27. Centro de Estudos Tributários e Aduaneiros, Secretaria da Receita Federal, Ministério da Fazenda. Análise de arrecadação das receitas federais. http://receita.economia.gov.br/dados/ receitadata/arrecadacao/relatorios-do-resulta do-da-arrecadacao/arrecadacao-2017/dezem bro2017/analise-mensal-dez-2017.pdf (acessa do em 05/Jul/2019).

28. Brasil. Lei no 13.414, de 10 de janeiro de 2017. Estima a receita e fixa a despesa da União para o exercício financeiro de 2017. Diário Oficial da União 2017; 11 jan.

29. Secretaria de Fazenda do Rio Grande do Sul. Balanço financeiro consolidado de 2018. https://cage.fazenda.rs.gov.br/conteudo/ 4793/balanco-financeiro---consolidado (acessado em 05/Mai/2019).

30. Centro de Estudos Avançados em Economia Aplicada. Mensuração econômica da incidência de pragas e doenças no Brasil: uma aplicação para as culturas de soja, milho e algodão. Parte 1. Piracicaba: Escola Superior de Agricultura "Luiz de Queiroz", Universidade de São Paulo; 2019.

31. Carbonar A, Andrade A, Lenat A, Masuko A, Andrade M, Parente W. Impacto do aumento de impostos de defensivos agrícolas. Brasília: Barral M. Jorge Consultores Associados; 2017.

32. Becker GS, Grossman M, Murphy KM. An empirical analysis of cigarette addiction. Am Econ Rev 1994; 84:396-418.

33. Gospodinov N, Irvine I. A long march's perspective on tobacco use in Canada. Canadian Journal of Economics 2005; 38:366-93.

34. Böcker T, Finger R. European pesticide tax schemes in comparison: an analysis of experiences and developments. Sustainability 2016; $8: 378$.

35. Instituto Brasileiro de Meio Ambiente. Consumo de ingredientes ativos de agrotóxicos no Brasil. Relatório Sintético. Brasília: Ministério do Meio Ambiente; 2014. 
36. Porto MFS. O trágico Pacote do Veneno: lições para a sociedade e a Saúde Coletiva. Cad Saúde Pública 2018; 34:e00110118.

37. Thomas JM, Callan J. Economia ambiental: aplicações, políticas e teoria. 2a Ed. São Paulo: Cengage Learning; 2016.

38. Terra FHB. A indústria de agrotóxicos no Brasil [Dissertação de Mestrado]. Curitiba: Programa de Pós-Graduação em Desenvolvimento Econômico, Universidade Federal do Paraná; 2008.

39. Lopes CVA, Albuquerque GSC. Agrotóxicos e seus impactos na saúde humana e ambiental: uma revisão sistemática. Saúde Debate 2018; 42:117.

40. Silveira JM. Estudos da competitividade industrial brasileira. Competitividade da indústria de defensivos agrícolas. Nota técnica setorial do complexo químico. Campinas: Universidade Estadual de Campinas/Universidade Federal do Rio de Janeiro/Fundação Dom Cabral/ Fundação Centro de Estudos do Comércio Exterior; 1993.

41. Brasil. Lei no 8.032, de 12 de abril de 1990. Dispõe sobre a isenção ou redução de impostos de importação, e dá outras providências. Diário Oficial da União 1990; 13 abr.
42. Brasil. Decreto no 6.759 , de 5 de fevereiro de 2009. Regulamenta a administração das atividades aduaneiras, e a fiscalização, o controle e a tributação das operações de comércio exterior. Diário Oficial da União 2009; 6 fev.

43. Brasil. Lei no 10.925, de 23 de julho de 2004. Reduz as alíquotas do PIS/PASEP e da COFINS incidentes na importação e na comercialização do mercado interno de fertilizantes e defensivos agropecuários e dá outras providências. Diário Oficial da União 2004; 26 jul.

44. Brasil. Decreto no 5.630 , de 22 de dezembro de 2005. Dispõe sobre a redução a zero das alíquotas da Contribuição para o PIS /PASEP e da COFINS incidentes na importação e na comercialização no mercado interno de adubos, fertilizantes, defensivos agropecuários e outros produtos, de que trata o art. 1o da Lei no 10.925, de 23 de julho de 2004. Diário Oficial da União 2004; 23 dez. 


\section{Abstract}

Pesticides are hazardous products, and fiscal incentives for such products directly and indirectly impact public resources for health in Brazil, since these incentives encourage pesticide use. The article thus aimed to estimate the tax relief for pesticides in Brazil in 2017. The methodology included a literature search on related tax legislation, followed by estimates based on pesticide expenditures according to the latest national Agricultural Census and foreign trade data. Tax exemptions on pesticides in 2017 totaled BRL 9.8 billion (USD 3.0 billion), of which: exemptions of BRL 6.2 billion (USD 1.9 billion) on value-added tax on sales and services, BRL 1.7 billion (USD 515 million) on excise tax, BRL 1.5 billion (USD 455 million) on social tax on net corporate income, and BRL 472 million (USD 143 million) on import tax. The results show that the efficiency of pesticide use is artificially overestimated by failing to take tax exemptions into account. Thus, taxation is a potential means for reducing the demand for pesticides, mitigating negative externalities and strengthening alternative and ecologically balanced agricultural practices.

Agrochemical; Tax Exemption; Livestock Industry

\section{Resumen}

Los pesticidas son productos peligrosos y los incentivos fiscales asociados a ellos impactan directa e indirectamente en los recursos públicos empleados en la salud de Brasil, puesto que estimulan su uso. Por ello, el objetivo de este artículo es estimar la exoneración fiscal sobre los pesticidas en el país durante 2017. La metodología incluyó la investigación bibliográfica de las legislaciones tributarias de referencia, seguida de las estimaciones calculadas a partir de los gastos con pesticidas, reveladas en el último censo agropecuario y datos de comercio exterior. El montante calculado $y$ consolidado en Brasil es del orden de BRL 9,8 billones, siendo que BRL 6,2 billones corresponden a la exoneración de ICMS (Impuestos sobre la Circulación de Bienes y Servicios), BRL 1,7 billones del IPI (Impuestos sobre Productos Industrializados), BRL 1,5 billones de contribuciones sociales y BRL 472 millones de impuestos de importación. Los resultados encontrados demuestran que la eficiencia del uso de pesticidas está artificialmente sobreestimada, debido a la exoneración fiscal. De esta forma, la tributación se presenta como un medio potencial de reducir la demanda de pesticidas, mitigando las externalidades negativas y fortaleciendo prácticas agrícolas alternativas y ecológicamente equilibradas.

Agrotóxicos; Exención de Impuesto; Industria Agropecuaria
Recebido em 25/Nov/2019

Versão final reapresentada em 26/Mar/2020

Aprovado em 31/Mar/2020 